ISSN 1982-8713

\title{
Formas de Representação das Candaces na Cultura Material em Kush (I AEC e I EC)
}

\author{
Forms of Representation of Candaces in Material Culture in Kush (I AEC \\ and $E C$ )
}

\begin{abstract}
Fernanda Chamarelli de Oliveira ${ }^{1}$
1 Mestra pelo Programa de Pós-graduação em História Social da Cultura, na Pontifícia Universidade Católica do Rio de Janeiro. Professora efetiva pertencente ao Departamento dos Anos Iniciais do Colégio Pedro II, Campus São Cristóvão I. Integrante do Laboratório de Estudos em Educação e Diversidade do Colégio Pedro II. E-mail: fchamarelli29@gmail.com.
\end{abstract}

Recebido em 21 de julho de 2020; Aceito em 2 de dezembro de 2020.

DOI: $10.12957 /$ nearco.2020.56683

\section{Resumo}

O presente artigo analisa formas de representação das candaces a partir da cultura material produzida em Kush, a fim de reconhecer o protagonismo da mulher no período do século I AEC ao I EC. Destacaremos a força feminina representada pelas figuras de Amanirenas e Amanitore, questionando as análises que visam demonstrar que seu poder ocorre em uma sociedade quando estas ocupam o lugar de governante central.

Palavras-chave: Candaces; Kush; Cultura Material.

\begin{abstract}
This article analyzes ways of representing candaces from the material culture produced in Kush, in order to recognize the role of women in the period from the 1st century BCE to the 1st CE. We will highlight the feminine strength represented by the figures of Amanirenas and Amanitore, questioning the analyzes that aim to demonstrate that their power occurs in a society when they occupy the place of central ruler.
\end{abstract}

Keywords: Candaces; Kush; Material Culture.

Introdução 
ISSN 1982-8713

Candace foi o nome conferido a mulheres que compunham a família do soberano no Reino Kush, localizado na região da África subsaariana, entre os séculos II AEC e IV $E C^{15}$, sendo suas mães, esposas e irmãs, assumindo importantes papeis sociais e políticos, atuando como conselheiras de seus maridos, irmãos ou filhos, e chegando a assumir o governo de forma autônoma e independente neste período. Essas mulheres se apresentam como figuras de destaque nos estudos africanos da antiguidade, representando a força da mulher como indivíduo ativo.

Comparadas às suas homólogas no Egito, as mulheres das famílias dos soberanos em Kush, no período do Reino de Napata, assumiram funções sociais e políticas mais relevantes. Elas são retratadas amamentando as divindades, derramando libações para as mesmas e acompanhando seus maridos nas situações em que eles celebravam esses rituais, que poderiam também ser comandados por estas mulheres.

A primeira soberana a assumir o título de Ktke, ou candace, parece ter sido Bartare, na metade do século II AEC. As informações sobre esta soberana ainda permanecem bastante imprecisas, mas de acordo com as inscrições em um cartucho que continha seu nome, ela teria recebido os títulos de "Filho de Rá, Senhor das duas Terras", título que era utilizado apenas pelos governantes egípcios. Bartare é reconhecida como sucessora direta do soberano Arakakamani ${ }^{16}$, o primeiro governante a ser enterrado em Méroe ${ }^{17}$, no cemitério ao sul da cidade, assim como esta soberana. No entanto, não existem comprovações de que ela teria de fato governado de forma autônoma, pois à mesma não era atribuído o título de qore, que pode ser compreendido

\footnotetext{
${ }^{15}$ Neste artigo optamos pelo uso das siglas AEC (Antes da Era Comum) e EC (Era Comum).

${ }^{16}$ HARKLESS, Necia Desiree. Nubian pharaohs and meroitic kings - the kingdom of Kush. Bloomington: Author House, 2006, 145.

${ }^{17}$ A cidade foi a segunda capital de Kush. A primeira se localizava na cidade de Napata.
} 
NEARCD: Revista Eletrônica de Antiguidade 2020, Volume XII, Número II - ISSN IS82-8713

Núclea de Estudas da Antiguidade - NEA

Universidade do Estado do Rio de Janeiro

ISSN 1982-8713

com o significado de chefe, pois era atribuído a soberanos governantes, sendo um título inicialmente masculino, e que passa a ser identificado somente na escrita meroítica. ${ }^{18}$

Apenas quatro governantes são conhecidas por terem utilizado o título de qore: Amanirenas, Amanishaketo, Nawidemak e Maleqereabar, todas por definição também candaces, representado em linguagem meroítica como $k d w e / k d k e l / k t k e$ e em egípcia como kn-tl-[k]y. Esse último termo, já conhecido inclusive na cultura helenística, era usado anteriormente ao governo da primeira governante feminina reconhecida, Shanakdakheto. Essas soberanas também receberam as titulações faraônicas de "Filho de Rá" e "Grande Senhor das duas Terras". Passaram a assumir papeis que eram restritos aos soberanos, como conquistar prisioneiros, ferir inimigos e oferecer presentes as divindades.

Existem diferentes interpretações em relação ao significado do termo candace. O mais usual traduz este como sendo a mãe do soberano governante ou a "rainha-mãe". Já alguns estudos apontam que uma interpretação mais correta do termo seria a de irmã do soberano ou "irmã real", pois, possivelmente, candace deriva de uma palavra meroítica que significa irmã, sendo uma variante do termo egípcio snt $n s w t$, conhecido como irmã do soberano ${ }^{19}$. Este termo teria sido utilizado pelas esposas dos soberanos na XVIII dinastia egípcia, bem como na XXV dinastia e no período napatano. A ênfase atribuída a este título no período meroítico pode estar associada a uma valorização destes períodos anteriores, onde os matrimônios entre irmãos dentro de uma mesma dinastia parecem ter sido determinantes em uma forma de legitimação "tradicional" em famílias "reais" 20.

\footnotetext{
${ }^{18}$ FAGE, J. D. The Cambridge history of Africa. Vol. 2: From c. 500 BC to AD 1050. Cambridge University Press, 2008, p. 241.

${ }^{19}$ TOROK, Laszlo. The kingdom of Kush: handbook of the Napatan-Meroitic civilization. Handbook of Oriental studies. Brill, 1997, p. 214.

${ }^{20}$ TOROK, Laszlo. The kingdom of Kush: handbook of the Napatan-Meroitic civilization. Handbook of Oriental studies. Brill, 1997, p. 214.
} 
ISSN 1982-8713

O termo candace é, desta forma, uma apropriação e tradução Greco-romana de uma palavra pertencente ao vocabulário kushita. Ele deriva da palavra de origem meroíta KTKE ou KDKE, que a partir de sua latinização, após o contato romano com esta sociedade, passa a significar "rainha-mãe". Esse termo alcançou maior importância e reconhecimento pela identificação destas mulheres como soberanas nos escritos e relatos feitos por narradores gregos e romanos. No entanto, o título de origem kushita não foi utilizado apenas para as soberanas que exerceram o poder central, mas para identificar e nomear as esposas, mães e irmãs dos governantes que possuíam um papel de extrema relevância ao seu lado no governo, bem como na legitimação de sua coroação.

O papel das candaces pode ser destacado a partir de sua relevante posição na eleição e coroação de seu filho enquanto governante e também na adoção da esposa de seu filho igualmente como sua filha, o que nos fornece dados para refletirmos sobre a importância dos laços maternais presentes nesta sociedade. O soberano era escolhido entre uma linhagem de "irmãos reais", participando desta escolha altos funcionários da corte, sacerdotes, chefes de clãs, chefes militares, e também a mãe, que assumia papel importante também na coroação do novo governante. ${ }^{21}$ Esse ato de adoção da esposa do filho nos leva a refletir sobre a concepção dos laços de maternidade que ligavam os diferentes membros de uma unidade de parentesco. Ao adotar a nora, esta passa a constituir a família do governante e se liga a ele por uma maternidade em comum, possibilitando-nos pensar que o entendimento do ser mãe na sociedade kushita não se relaciona apenas com uma questão biológica, mas com o pertencimento a um grupo de indivíduos que se conectam a partir de laços definidos por essa figura materna.

A partir do que foi dito faremos uma análise sobre as representações das Candaces no reino de Kush, região da Núbia (atual Sudão), entre os séculos I AEC e I EC.

\footnotetext{
${ }^{21}$ A. M. ALI HAKEM. A civilização de Napata e Méroe. In: MOKHTAR, G. (coord.). História Geral da África. v. 2: A África Antiga. São Paulo - Paris: Ática - UNESCO, 1983, p. 304.
} 
A análise dessas representações nos permitirá fazer uma discussão sobre o lugar do feminino e da maternidade na África Antiga (Egito e Núbia). Partindo da proposta que o protagonismo da mulher no Reino Kush se dá por sua posição social assumida enquanto mãe, posição esta considerada como algo quase divino, buscaremos apresentar dados que demonstrem que este lugar assumido pelas governantes está ligado ao lugar que as mulheres ocupavam na sociedade a partir dos laços da maternidade.

Propomos uma análise da estela de Hamadab, do século I AEC, onde Amanirenas é retratada como líder política e militar do reino Kush, sendo retratada ao lado de uma figura masculina, que se acredita ser seu filho Akinidad, e do templo de Apedemak, localizado na cidade de Naga, construído aproximadamente entre os séculos I AEC e I EC, onde estão retratadas imagens de Amanitore e de seu marido Natakamani, com status de igualdade e em justaposição. Discutiremos a questão de que se por um lado a liderança do governo era exercida pelo homem, Natakamani, isto não estabelece uma desigualdade que esteja relacionada com a questão de gênero. Sendo o governo central assumido pelo homem, este contava com a legitimação de seu poder pela mulher, que possuía uma posição de respeito e importância seja dentro do ambiente doméstico, em sua comunidade ou como mãe, irmã, esposa e conselheira do rei.

\section{A estela de hamadab e a complementaridade entre o feminino e masculino}

A estela de Hamadab, também conhecida como Grande estela de Amanirenas e seu filho, nos traz uma representação importante sobre a questão da complementariedade entre o feminino e o masculino na busca pelo equilíbrio e sustentação do governo ${ }^{22}$. A candace Amanirenas foi esposa do governante Teriteqas e aparece sendo representada junto a ele em dois locais, em um grafite presente no

\footnotetext{
${ }^{22}$ Considerações sobre Akinidad e as funções exercidas por ele em: EIDE, Tormod et alli. Fontes Historiae Nubiorum: Textual Sources for the History of the Middle Nile Region between the Eighth Century BC and the Sixth Century AD. Vol. I, II e III, 1998, p. 719.
} 
Templo de Thoth, em Dakka e no texto da estela deste soberano na cidade de Méroe, no Templo $\mathrm{M}$, tendo em ambos o seu nome marcado em inscrições cursivas meroíticas.

A estela foi encontrada na cidade de mesmo nome, ao sul da cidade de Méroe, por John Garstang. Se caracteriza por ser a mais conhecida e a mais longa escrita real, com 42 linhas, gravada em texto meroítico encontrada nos templos de Napata e Méroe, dentre as pertencentes ao século I AEC. Foi confeccionada em arenito e possui altura de 236,5 centímetros e largura de 101,5 centímetros. ${ }^{23}$ Atualmente se encontra como acervo do Museu Britânico, na cidade de Londres, se localizando no departamento do Egito Antigo e Sudão, e tendo sido adquirida em 1914. A estela se encontra incompleta, pois seu topo foi perdido.

Essa estela foi encontrada por Garstang em um templo de dimensões pequenas, quando comparado a outros edifícios similares do mesmo período. O templo apresentava uma estrutura geral bastante incomum, pois possuía uma extensão em seu lado norte de cinco quartos anexos, que aparentemente tiveram uma função substancial para o edifício. Em si, o santuário se compunha de três salas principais, que se organizavam ao longo de seu eixo principal, sendo duas antecâmaras divididas por um par de colunas e o santuário. ${ }^{24}$

As paredes do templo eram feitas de barro e possuíam aproximadamente 1,80 de espessura. As paredes exteriores, assim como os batentes de porta em arenito tinham acabamento em gesso de cal. O santuário foi pavimentado com tijolos queimados, enquanto as antessalas possuíam chão de terra batida. Não se pode precisar qual divindade havia sido adorada no santuário, pois não existem pinturas ou relevos preservados nas paredes, além da incomum estrutura do edifício. É possível que tenha

\footnotetext{
${ }^{23}$ HARKLESS, Necia Desiree. Nubian pharaohs and meroitic kings - the kingdom of Kush. Bloomington: Author House, 2006.

${ }^{24}$ NOWOTNICK, Ulrike. (et alli). Hamadab. Urban living at the Nile in Meroitic times. German Archaeological Institute Orient Department, Hamadab Archaeological Project, Berlin, University of Liverpool, 2014, p. 5
} 
ISSN 1982-8713

sido um templo de Amon, por se tratar de uma alta divindade do panteão kushita, ou que tenha sido utilizada para funções variadas que não apenas de adoração divina. ${ }^{25}$

Foram encontrados no templo objetos votivos e um mobiliário de culto preservados, onde se podem identificar figuras de leão, esfinges, uma mesa de oferendas de bronze e madeira petrificada, uma estátua de arenito e uma estatueta de bronze. Esta última peça aparenta ter as características da divindade meroítica Sebiumeker, associado a procriação e a fertilidade, e também relacionado a um guardião de portas de entrada, pois muitas vezes era encontrado sendo posicionado próximo a estas. $^{26}$

A frente do templo se encontra um amplo espaço aberto que provavelmente serviu como local de realização de cerimônias religiosas e oficiais, onde era possível observar duas estelas monumentais que faziam referência a candace Amanirenas e a Akinidad. No átrio existia um pequeno altar aberto, cerca de vinte centímetros a frente do templo, onde se realizavam rituais e oferendas. Seu altar era feito de alvenaria de tijolos queimados, como pilastras de arenito e gesso branco. ${ }^{27}$

\footnotetext{
${ }^{25}$ Ibidem, p. 6.

${ }^{26}$ NOWOTNICK, 2014, op. cit., p. 6.

${ }^{27}$ Ibidem, p. 6-7.
} 


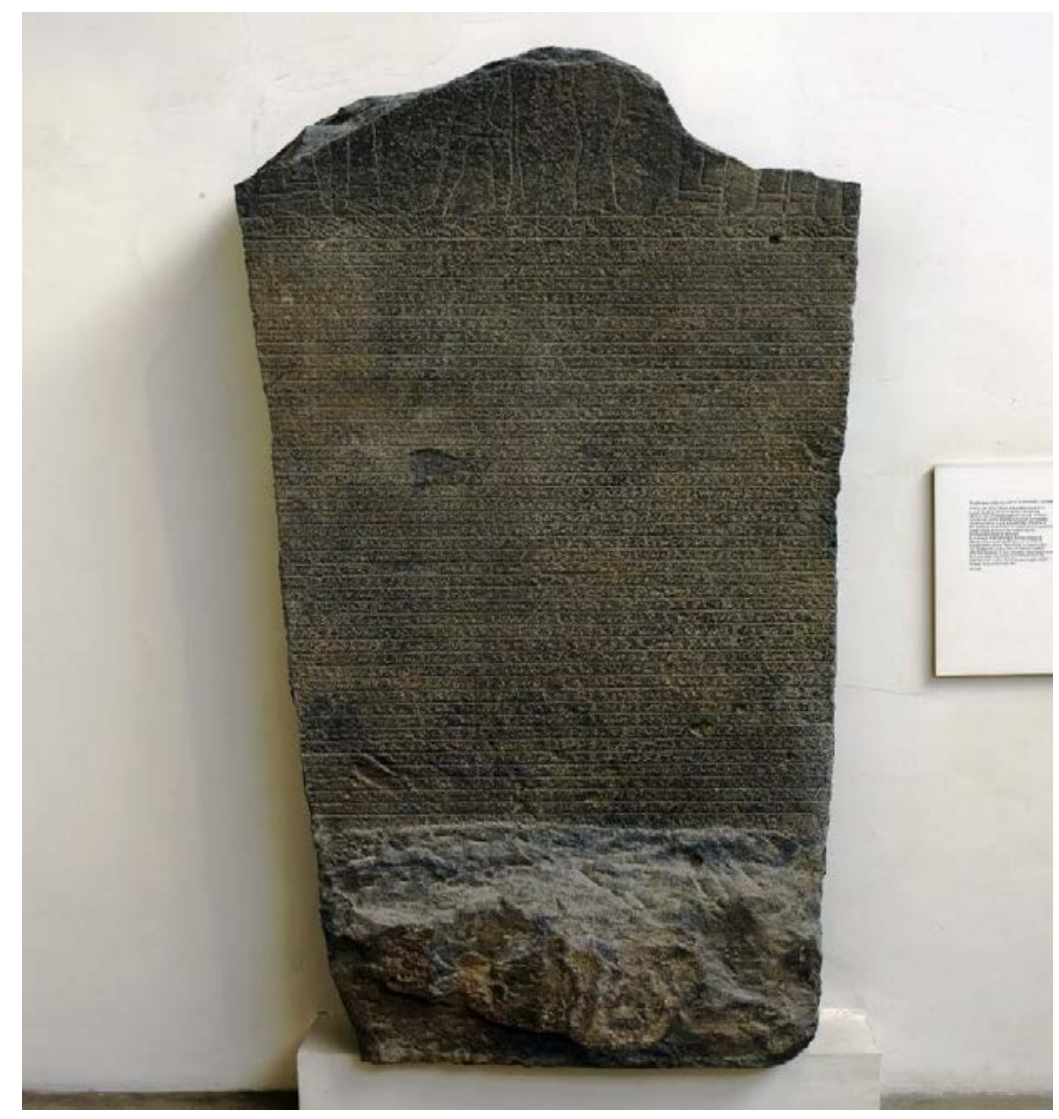

Figura 1. Estela de Hamadab. Referência:

https://www.britishmuseum.org/research/collection online/collection object details.aspx?objectld=11

\section{$6018 \&$ partld $=1 \&$ object $=20160 \&$ sortBy $=i m a g e$ Name \&page $=1$}

A estela que aqui analisamos é reconhecida por ter sido confeccionada como uma celebração de campanhas militares, onde Amanirenas é retratada junto a Akinidad, pois é possível observar que no friso abaixo dos soberanos são retratados dez prisioneiros que aparecem ligados e subjugados a eles. Para melhor compreendermos a simbologia presente nesta estela, nos parece importante considerar tanto a iconografia nela presente, como o local onde ela estava disposta. Estando posiciona a frente de um templo, ainda que se trate de um santuário pequeno, principalmente se comparado a monumentalidade das estelas que ali estavam, se entende que havia uma busca no 
sentido de que as obras fossem visualizadas por um grande número de pessoas, e que, além disso, causasse grande impacto sobre elas.

Para além da questão da importância de uma ampla visualização das estelas, o fato de sua localização ser em um santuário, nos leva a refletir sobre a estreita ligação entre a religiosidade e o poder político em Kush. Era pela força das divindades de seu panteão que conquistas eram reconhecidas, governos legitimados e a ordem social era mantida. Se trata também de compreender o quanto determinados lugares sociais, como os ocupados pelas candaces, por exemplo, estavam em profunda ligação com a ordem cósmica, tendo suas funções amparadas pelo poder das divindades.

Na estela, Amanirenas é representada com uma túnica até a altura do tornozelo e sandálias, enquanto Akinidad aparece descalço e vestindo uma túnica. Segundo Lazlo Torok (1998), é possível observar, a partir do reconhecimento de algumas palavras em linguagem meroítica já conhecida e traduzidas, que Amanirenas é apresentada com os títulos de chefe (qore) e candace ( $k d w e$ ), enquanto Akinidad aparece como "príncipe" e com um alto título de governante utilizado na linguagem meroítica. Observamos que, sendo Amanirenas a governante central no período de construção da estela, ela não aparece sozinha nesta representação, e, através da análise das titulações, vemos que o elemento masculino atua como co-regente, nos levando a refletir sobre a questão da complementariedade que se mostra presente nesta representação. ${ }^{28}$

A mesma lógica de pares complementares observada na representação da estela, e também associada em grande parte a questão da religiosidade, pode ser observada em deuses do panteão egípcio, que estão relacionados ao mito de criação do mundo, sendo aqui utilizado como referência o mito de Heliópolis. ${ }^{29}$ Atum, a divindade

\footnotetext{
${ }^{28}$ EIDE, Tormod et alli. Fontes Historiae Nubiorum: Textual Sources for the History of the Middle Nile Region between the Eighth Century BC and the Sixth Century AD. Vol. I, II e III, 1998, p. 719-722.

${ }^{29}$ Os mitos egípcios de criação do mundo se constituem em objeto de grande relevância para o entendimento da cultura e da religiosidade da sociedade. Os egípcios criaram um sistema religioso para explicar o nascimento ou origem do mundo e assim buscavam justificar suas crenças. Cada centro religioso
} 
NEARCD: Revista Eletrônica de Antiguidade 2020, Volume XII, Número II - ISSN IS82-8713

Núclea de Estudas da Antiguidade - NEA

Universidade do Estado do Rio de Janeiro

ISSN 1982-8713

criadora, traz à Terra inicialmente duas personificações de elementos femininos, lusaas e Nebet-Hetepet ${ }^{30}$, que são diretamente associadas à Hathor, como filhas do criador. São elas que com sua beleza colaboram para que Atum prossiga com seu ato de criação. À divindade Hathor são atribuídas categorias binárias relacionais como as de mãe e filha, celibatária e mãe, pai e filha, esposa e esposo. ${ }^{31} \mathrm{O}$ ato de criação prossegue com pares de divindades, sendo os primeiros, Tefnut (deusa da água) e Shut (deus do ar); seguidos por Nut (deusa do céu) e Geb (deus da terra), que são separados, dando forma ao céu, a terra e a atmosfera conforme conhecemos; Osiris (deus dos mortos) e Isis (deusa mãe); Seth (deus do caos) e Néfti (irmã de Isis e guardiã dos mortos), como podemos observar na imagem abaixo. ${ }^{32}$

Essas relações que passam a ser observadas a partir da criação da divindade Hathor e os termos que são a ela direcionados, nos auxiliam na compreensão das variadas referências que são utilizadas pelos elementos femininos que cercam o soberano, entendendo também a importância das mesmas. Aquela que é reconhecida como mãe, também é nomeada como irmã e esposa, pois estes termos são relacionais e também se apresentam como diretamente ligados a uma criação de vida e potência que é entendida como só possível de acontecer quando existe a dualidade complementar entre o masculino e o feminino. Hathor assumiu tanto o uso da categoria de filha da divindade criadora como a de esposa, pois ela foi força através da qual foi

elaborou uma cosmogonia, sendo a mais reconhecida, a de Heliópolis. Ver HART, George. Mitos egípcios. Moraes, São Paulo; 1992.

30 lusaas ou lusaaset é uma divindade do panteão egípcio reconhecida como avó de todas as divindades. Era representada usando a coroa de abutres de Mut, tendo acima destas o disco solar entre os chifres de vaca, símbolo da divindade Hathor. Já Nebet- Hetepet é também uma divindade egípcia reconhecida como "senhora das oferendas", sendo cultuada em Heliópolis como a contrapartida feminina de Atum. Ela se constituía como o princípio feminino da criação, personificando a mão de Atum.

${ }^{31}$ SEVILLA CUEVA, Covadonga. El principio femenino de la realeza egipcia: Las divinas adoratrices de Amón. Madrid: Universidad Autónoma de Madrid, 1998, p. 256-257.

32 GRAVES-BROWN, Carolyn. Dancing for Hathor. Women in Ancient Egypt. Londres e Nova York: Hambledon Continuum, 2010, p. 132. 
possível para Atum prosseguir a criação, assim como mãe, pois estava conectada ao processo que levou ao surgimento de outras divindades. Da mesma forma, a mãe do soberano também aparece como esposa ou irmã, pois liga-se ao fato de buscar junto ao elemento masculino esta força criadora.

Ainda refletindo sobre esta concepção teológica, a divindade Atum centraliza em si próprio as qualidades femininas e masculinas, que são expandidas após a criação do primeiro casal divino, representado por Shu e Tefnut, que possuíam os caracteres do "pai" e seriam, desta forma, uma manifestação da dualidade que se encontrava presente em uma única divindade. ${ }^{33} \mathrm{Em}$ nossa análise, não acreditamos que esta dualidade tenha gerado um divisão de gêneros tal qual conhecemos no pensamento ocidental, mas sim que representava a consciência da importância do elemento masculino e feminino para a continuidade da vida, não havendo uma sobreposição de um sobre o outro.

Quando analisamos o papel assumido por Shu e Tefnut após a sua criação, sendo reconhecido por Atum, como seus filhos e tendo relação de irmãos, e também sendo capazes de gerar outras divindades, podemos fazer uma analogia com a função que era assumida pelas mulheres que compunham os laços mais próximos ao soberano, tanto no Egito como na Núbia, e os títulos que a elas eram concedidos, como irmã/mãe/esposa do soberano, pois todas as divindades possuem seus elementos complementares, e aquelas que seriam as esposas, são também as irmãs, assim como mães de uma outra divindade. Como se esperava uma proximidade dos soberanos com os deuses, era comum que existisse uma associação entre a composição de suas "famílias".

Ao refletirmos sobre esta questão a partir da figura do soberano, percebemos que esta complementariedade aparece estabelecida no momento em que o mesmo é

\footnotetext{
${ }^{33}$ SALES, José das Candeias. Organizando simbolicamente o panteão do antigo Egipto. As tríades divinas. Revista Mundo Antigo - Ano V, Vol. V, Nº9 - Maio - 2016, p. 236.
} 
acompanhado de sua esposa ou mãe, demonstrando uma justaposição, onde o masculino e o feminino formam uma unidade que garante uma contínua renovação. $A$ figura da mãe do governante representa uma união a ancestralidade, a geração anterior, enquanto junto com a figura de sua esposa, o soberano poder continuar sua geração e influenciar o futuro. Observamos assim a importância do aspecto feminino junto ao soberano, pois sem ele sua investidura no cargo, que é dada a partir de sua descendência materna, e sua prosperidade em seu governo, alcançada junto a sua esposa, não seriam possíveis.

Em comparação com a Estela de Hamadab até agora analisada, podemos ver que esta justaposição entre o masculino e o feminino também pode ser identificada na constituição das tríades divinas, que são muito presentes no panteão egípcio, mas também se mostram com certa importância na Núbia. Sendo consideradas como associações que remetem a uma unidade, apesar de não serem comumente citadas nos textos egípcios, eram bastante frequentes, como podemos observamos nos seguintes exemplos: Osíris, Isis e Hórus (Abidos), Ptah, Sekhemet e Nefertum (Mênfis), Amon, Mut e Khonsu (Karnak), Khnum, Satet e Anuket (Elefantina), Khepri-Ré-Atum (Heliópolis); Ptah-Sokaris-Osiris (Mênfis), Hathor, Hórus e Ihy (Dendera). Na Núbia podemos identificar a tríade Apedemak-Isis-Hórus, em Naga. ${ }^{34}$

A partir do estudo da estela de Hamadab e das tríades divinas do panteão egípcio, nos parece importante nos questionarmos se esta questão da maternidade era considerada por estas sociedades apenas em seu aspecto biológico ou se assumia um outro sentido simbólico relacionado a capacidade da mulher de gerar uma nova vida, de manter a existência da comunidade, e por isto ter proximidade a divindades femininas, ou se existiria uma concepção de maternidade compartilhada, onde os responsáveis

\footnotetext{
${ }^{34}$ SALES, José das Candeias. Organizando simbolicamente o panteão do antigo Egipto. As tríades divinas. Revista Mundo Antigo - Ano V, Vol. V, Nº 09 - Maio - 2016, p. 226.
} 
pelo cuidado e educação da criança partilhassem desse laço. De acordo com Silke Roth ${ }^{35}$, analisando a relevância das soberanas enquanto mães no Egito, a proeminência de seu papel ocorria devido a sua capacidade biológica de garantir a sucessão no trono, mas que, na verdade, assume um papel que se apresenta de forma muita mais ideológica dentro da construção da ideia de renovação contínua na "realeza".

Segundo a autora, aquele que assumia o governo não possuía necessariamente filho biológico dos soberanos anteriores. Existiram casos de manutenção do direito hereditário, porém o novo governante poderia conquistar essa posição por designação do antecessor ou por controle do poder. Ele então seria legitimado pelo próprio ato de manter a soberania como Hórus, ou seja, através de uma legitimação divina. Esse novo soberano passaria então a ser consequentemente considerado como filho de seu predecessor. Desta forma, o papel de legitimação exercido pela soberana teria uma relação muito mais ideológica, pois ela representaria a contraparte feminina nesta legitimação divina, por seu poder de conceber a vida, do que de fato biológico. ${ }^{36}$

Em vida, esse governante era a representação de Hórus e após sua morte, de Osiris. Desta forma, as mães e esposas do governante, assim como as deusas, assumiam a posição de sua consorte. Essas mulheres apareciam representadas junto aos soberanos e como as deusas poderiam ser mostradas com um aspecto maternal, mas também extremamente protetora. O soberano egípcio só poderia governar juntamente com sua contrapartida feminina, que era responsável pela fecundidade do Egito, eram parte de um pequeno grupo de pessoas que poderia adentrar em lugares sagrados junto ao soberano e participava de rituais religiosos como os de coroação e entronamento.

\footnotetext{
${ }^{35}$ ROTH, Silke. Queen. In Elizabeth Frood, Willeke Wendrich (eds.). UCLA Encyclopedia of Egyptology, Los Angeles. UCLA, 2009, p. 5.

${ }^{36}$ ROTH, Silke. Queen. In Elizabeth Frood, Willeke Wendrich (eds.). UCLA Encyclopedia of Egyptology, Los Angeles. UCLA, 2009, p. 5.
} 
NEARCD: Revista Eletrônica de Antiguidade 2020, Volume XII, Número II - ISSN IS82-8713

Núcleo de Estudas da Antiguidade - NEA

Universidade do Estado do Rio de Janeiro

ISSN 1982-8713

Segundo Joyce Tyldesley ${ }^{37}$, no Egito, a mãe e a esposa, enquanto elementos femininos da "realeza", a partir da posição semidivina do soberano, assumiam posição bastante distintas de outras mulheres egípcias. Elas faziam parte de um amplo lar coletivo relacionado ao governante, que era formado por outras esposas, mães, irmãs, filhas e outros elementos femininos próximo ao soberano.

O elemento feminino, aquela que assume o papel de mãe, é reconhecida como uma incorporação terrena da divindade Hathor, mãe de Hórus, como uma forma de garantir um meio regenerativo para o soberano, em sua função de governante, sendo representante da divindade principal no mundo terreno. É a partir da conexão desta divindade com sua contrapartida feminina, representada por aquela que assumia 0 papel de mãe, que ele procriaria uma forma rejuvenescida de si mesmo. A legitimação do governante, que assumia o lugar de seu filho, pela soberana estava então diretamente relacionada com a ideologia do parentesco divino que este novo representante teria, o que pode ser observado por títulos que se referiam à mãe, como o de $z A t n T r$, "filha do deus" e mwt nTr, "mãe do deus". ${ }^{38}$

De acordo com Massimiliano Nuzzolo

Em primeiro lugar, no estudo desta documentação, o termo "rainha", como usado no sentido moderno, poderia ter conotações que não espelham todo o espectro de papéis familiares. A mãe real, ao contrário, representa o aspecto feminino da realeza como tal, desempenhando um papel-chave como mãe e esposa, bem como como filha e irmã do rei. Seus padrões parecem ser adaptados aos do rei; é ele quem representa a manifestação terrena do poder do criador, cuja identidade andrógena é um composto de elementos femininos e masculinos, como se mostra claramente nos mitos da criação, renovação e ressurreição. A interação de elementos femininos e masculinos que, em sua união, dão origem à dinâmica de criação e poder, é assim reiterada nos mais importantes símbolos da realeza. Isto é visto, por exemplo, nas Duas Damas assim como nas duas Coroas, cujas imagens estão

\footnotetext{
${ }^{37}$ TYLDESLEY, J. Chronicle of the queens of Egypt. London: Thames \& Hudson,2006, p.6

${ }^{38}$ ROTH, Silke. Queen. In Elizabeth Frood, Willeke Wendrich (eds.). UCLA Encyclopedia of Egyptology, Los Angeles, UCLA, 2009, p.5.
} 

complementares e simétricas aos elementos feminino e masculino. ${ }^{39}$

Desta forma, segundo Nuzzolo ${ }^{40}$, é a forma de organização da "realeza" que fundamenta neste sentido os princípios básicos para esta simbologia, onde a mãe, o elemento feminino, a partir de suas participações em diferentes cerimônias e rituais relacionados ao governante, adquire importante papel sendo reconhecida como uma manifestação de protótipos femininos divinos, como Hathor e Isis, por exemplo, como fonte essencial para a realização de cultos e rituais, e como elemento fundamental de renovação de direitos tanto terrenos quanto divinos que garantiam que o soberano pudesse assumir sua função.

Através da análise de alguns nomes e termos reconhecidos presentes na estela, em linguagem meroítica, algumas considerações importantes podem ser apontadas, especialmente no que se refere a posição ocupada em Kush tanto por Amanirenas quanto por Akinidad, assim como também nos possibilita ter uma base para compreendermos os motivos pelos quais tal estela foi construída e posicionada em um local de importante acesso como no santuário situado na cidade de Hamadab.

De acordo com Torok ${ }^{41}$, Griffit (1917) interpretou o texto presente na estela como menções ao combate contra os romanos entre 25-24 AEC. Já na análise de Hintze (1959), as menções seriam dedicadas a mostrar apenas os episódios iniciais da batalha somente, revelando o sucesso nos ataques a Philae, Syene e Elefantina, cidades egípcias que se encontravam sob domínio romano. Essas interpretações estão baseadas na

\footnotetext{
${ }^{39}$ NUZZOLO, Massimiliano. The royal mother in the Ancient Egyptian Kingdom: role, representation and cult. In: Proceedings of the Second International Congress for Young Egyptologists. Lisboa, 23-26 October 2006, Lisboa 2009, p. 420.

40 Ibidem, p. 421.

${ }^{41} \mathrm{EIDE}$, Tormod et alli. Fontes Historiae Nubiorum: Textual Sources for the History of the Middle Nile Region between the Eighth Century BC and the Sixth Century AD. Paperback, 1998, p. 721.
} 
identificação das palavras Arme e Qes, que foram compreendidas como se referindo a Roma e Kush. ${ }^{42}$

O texto presente na estela, segundo Torok ${ }^{43}$, foi analisado em detalhe por Hofmann (1981), e a partir de suas considerações, apesar de muitos problemas gramaticais e de não se poder considerar uma possível reconstrução histórica somente a partir do texto, podemos refletir sobre as referências que são feitas para melhor compreender o papel assumido no governo por Amanirenas e Akinidad.

Nas linhas 1 e 2 da estela é possível observarmos os termos qore, que como já mencionado, seria utilizado para se referir a governante, e $k d w e(=K d k e)$, ou seja, Candace, ambos usados para se referir a Amanirenas. Nas mesmas linhas se identificam os termos qore(ñ?)-yi, um composto que contem a palavra usada para governante, mas ainda não compreendido em sua totalidade, além de pqr e pesto, que seria equivalente ao título de vice-rei que era utilizado na região da Baixa Núbia, todos fazendo referência a Akinidad. Nas linhas 2 e 3 há uma repetição dos termos pqr qori-se, "pqr of the ruler", o que pode demonstrar que Akinidad atuaria de forma bastante efetiva no governo de Amanirenas, talvez como seu co-regente. ${ }^{44}$

Nas linhas 2 e 3 há uma frase longa que se inicia com pqr qori-se-1 qor hrphe Iw qes arme-yose-li, que parece indicar, se a interpretação das palavras arme e qes estiverem corretas, o início da narrativa que tratará do conflito entre romanos e kushitas. $^{45}$

\footnotetext{
${ }^{42}$ EIDE, Tormod et alli. Fontes Historiae Nubiorum: Textual Sources for the History of the Middle Nile Region between the Eighth Century BC and the Sixth Century AD. Paperback, 1998, p. 721.

${ }^{43}$ Ibidem, p. 722.

${ }^{44}$ A análise é feita por Hofmann (1981) e descrita por Torok em: EIDE, Tormod et alli. Fontes Historiae Nubiorum: Textual Sources for the History of the Middle Nile Region between the Eighth Century BC and the Sixth Century AD. Paperback, 1998, p. 722.

${ }^{45}$ Ibidem, p. 722.
} 
Na linha 4, existem dois termos reconhecidos, $a b r$, que seria uma referência a homem, e kdi, a mulher. Na linha 5, o termo qo-leb, qo foi interpretado como "pessoa viva", por Griffith (1917, p. 167), Hintze (1960, p. 148). ${ }^{46}$

Nas linhas 18 e 19 foi identificado um pronunciamento que se iniciaria com o termo qor, também utilizado para se referir a governante, e fazendo referência a $A m n=A m o n, A m n p=A m o n$ de Luxor, e contendo os advérbios mlo, traduzido como bom, e Ih como grande, ótimo. Na linha 20 se observa novamente uma citação a Amon de Luxor, no termo Amnp, e também a Méroe, Mdewi. ${ }^{47}$

Na linha 26 aparentemente uma nova parte da narrativa é iniciada, começando com o nome e os títulos de Akinidad. Enquanto na primeira parte se identificam menções a termos reconhecidos como usados para homem e mulher e também a quantidades, que podem fazer referência a prisioneiros, a segunda parte contendo menções a Amon (Mno) parece se referir a ações reais conectadas a cultos a divindades. ${ }^{48}$

\footnotetext{
${ }^{46}$ EIDE, Tormod et alli. Fontes Historiae Nubiorum: Textual Sources for the History of the Middle Nile Region between the Eighth Century BC and the Sixth Century AD. Paperback, 1998, p. 722.

47 Ibidem, p. 722.

${ }^{48}$ Ibidem, p. 722.
} 


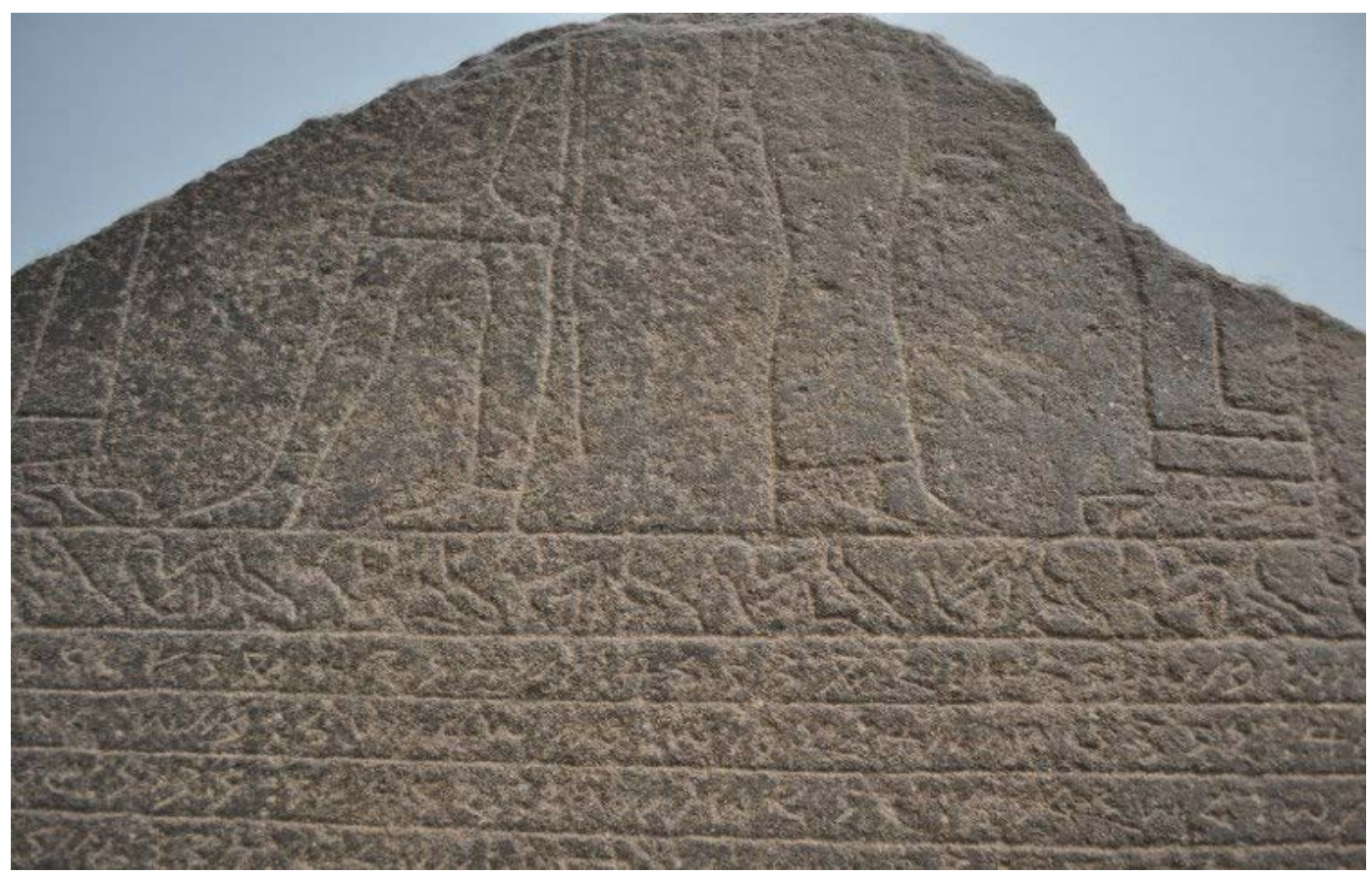

Figura 2. Detalhe do topo da Estela de Hamadab. Referência: Site do Museu Britânco

https://www.britishmuseum.org/research/collection online/collection object details/collection image gallery . aspx? partid=1\&assetid $=1345121001 \&$ objectid $=116018$

Aqui, duas destas interpretações nos chamam atenção, quando pensadas e analisadas junto a cena representada na estela, sendo elas a presença dos possíveis $\operatorname{cativos}^{49}$ abaixo da soberana e das divindades, e a importância da ligação entre o culto aos deuses e o reconhecimento e legitimação tanto do governo quanto da vitória no embate militar, o que era esperado do governante para que fosse possível manutenção da ordem no período em que o soberano estivesse na posição de liderança.

\footnotetext{
${ }^{49}$ Utilizamos o termo cativo para nos referirmos àqueles que eram considerados inimigos, tomados como prisioneiros após a derrota em combates. Segundo Florian Wob, desde o período pré-dinástico no Egito, representações mostravam inimigos em campos de batalha, prisioneiros sendo deslocados ou mortos, sendo entendidos como a parte que perturbava a ordem e a paz que deveriam ser mantidas pelos governantes. Ver WOB, Florian The representation of captives and enemies in meroitic art. In: ZACH, Michael H. (edit). Proceedings of the 11th international conference for meroitic studies. Viena, $1-4$ de setembro, 2008, p. 585-586.
} 
ISSN 1982-8713

\section{Candace amanitore e a co-regência em kush}

Amanitore e o soberano Natakamani foram os governantes em Kush em um dos períodos de maior prosperidade do reino, ao considerarmos a quantidade, bem como a qualidade de monumentos que foram por eles construídos ou restaurados, entre os quais podemos citar a construção dos Templos de Amon em Naga e o último a ser dedicado a esta divindade em Méroe, o Templo de Isis em Wad ban Naqa e o Templo de Apedemak em Naga. ${ }^{50}$ Eles podem ser reconhecidos como o mais relevante exemplo de co-regência e da existência de uma complementariedade entre os elementos masculino e feminino em Méroe.

Seu governo data de finais do século I AEC e início do século I EC ${ }^{51}$, ocorre após a administração da soberana Nawidemak, que é reconhecidamente a terceira soberana em sequência a assumir o governo de forma autônoma, tendo sido precedida por Amanirenas e Amanishakheto, respectivamente. Desta soberana existem referências que comprovam seu reinado, como a atribuição do título de qore, que aparece em inscrições em linguagem meroítica juntamente a seu nome, e a presença em iconografia a ela relacionada, de vestimentas e insígnias similares as utilizadas por soberanos kushitas. Em uma estátua de ouro localizada em Khartoum e na iconografia presente em sua capela funerária, é possível observarmos Nawidemak usando uma faixa, um cordão de pendão e vestes comuns aos soberanos. Seu sucessor foi, possivelmente seu filho Amanikabale. ${ }^{52}$

No governo de Amanitore e Natakamani, o que nos chama atenção primeiramente é o fato de que, em suas inscrições reais, seus nomes aparecem de forma

\footnotetext{
${ }^{50} \mathrm{EIDE}$, Tormod et alli. Fontes Historiae Nubiorum: Textual Sources for the History of the Middle Nile Region between the Eighth Century BC and the Sixth Century AD. Paperback, 1998, p. 899.

${ }^{51}$ Segundo HARKLESS, 2006, op. cit., p. 149, aproximadamente entre 12 AEC e 12 EC.

52 HARKLESS, 2006, op. cit., p. 148.
} 
NEARCD: Revista Eletrônica de Antiguidade 2020, Volume XII, Número II - ISSN IS82-8713

Núcleo de Estudas da Antiguidade - NEA

Universidade do Estado do Rio de Janeiro

ISSN 1982-8713

similar e ambos são representados juntos na iconografia, utilizando vestimentas e insígnias de soberanos. No que se refere a titulações, que são encontradas em hieróglifos egípcios e meroíticos, Natakamani é reconhecido como qore e recebe a titulatura comum ao soberano de Filho de Rá, enquanto Amanitore é Candace e também o título de "a grande, senhora das Duas Terras", titulatura que se assemelha bastante a usada pelas mães dos soberanos no período napatano ${ }^{53}$. Ela também recebe o título de Filha de Rá, em um cartucho, estando este possivelmente associado a titulaturas de soberanas ptolomaicas e o de "senhora dos diademas", relacionado a algumas Esposas de Amon. ${ }^{54}$ Inicialmente, ao considerarmos as titulaturas, podemos pensar que Amanitore era mãe ou consorte de Natakamani, assumindo um papel de não regente.

No entanto, quando analisamos na iconografia a forma como esta soberana era representada, percebemos que sua participação no governo ocorria de maneira efetiva e equivalente a Natakamani. Analisaremos aqui representações presentes no Templo de $\mathrm{Naga}^{55}$, sendo possível observarmos que ambos são retratados do mesmo tamanho, com vestimentas e insígnias reais e com uma simetria, existindo uma imagem como a de um espelho, onde cada ação e posição do soberano possui uma representação idêntica de Amanitore. Esse modelo iconográfico adotado difere de forma significativa

\footnotetext{
${ }^{53}$ EIDE, Tormod et alli. Fontes Historiae Nubiorum: Textual Sources for the History of the Middle Nile Region between the Eighth Century BC and the Sixth Century AD. Paperback, 1998, p. 897.

54 Ibidem, p. 903.

55 O templo de Apedemak, deus guerreiro com cabeça de leão adorado na Núbia, localiza-se na cidade de Naga, no atual Sudão. No mesmo sítio arqueológico estão o templo de Amon e um templo romano. 0 templo de Apedemak está a oeste do templo de Amon e é considerado um grande exemplo da arquitetura de Méroe. A arquitetura do templo mostra forte influência da arquitetura egípcia, porém é possível notar algumas diferenças, que representam a arte meroítica, na forma como se apresentam as imagens de Natakamani e Amanitore. Eles são representados com cabeças redondas e ombros largos e a ela aparece com quadris largos, o que é típico da arte africana. As roupas e ornamentos representados em suas figuras também são tipicamente meroíticos. https://en.wikipedia.org/wiki/Naqa
} 
daquele utilizado anteriormente, onde a mãe ou consorte do soberano, em geral, aparecia como que o seguindo, mostrando a figura do governante como a central. ${ }^{56}$

Ao serem representadas de forma idêntica e lado a lado, as cenas de Amanitore e Natakamani nos parecem demonstrar que eles atuavam de maneira conjunta e que não haveria a centralidade da regência em apenas um dos elementos. Na imagem abaixo podemos observar estes soberanos à frente do templo, estando Natakamani à direita e Amanitore à esquerda. Eles aparecem exercendo seu poder militar e divino sobre prisioneiros, sendo este poder simbolicamente representado pela imagem de leões em seus pés. Considerando a importância de Apedemak para esta sociedade, observamos aqui, como anteriormente, uma relação entre a legitimação do poder dos soberanos através de seu reconhecimento e proteção garantida por esta divindade. Tal ligação também pode ser observada pela presença da divindade Apedemak nas bordas deste templo, onde aparece com sua cabeça de leão e o corpo de serpente, emergindo de uma flor de lótus. Nas laterais ainda se encontram imagens de outras divindades, sendo estas Amon e Hórus, na companhia de Natakamani.

\footnotetext{
${ }^{56}$ EIDE, Tormod et alli. Fontes Historiae Nubiorum: Textual Sources for the History of the Middle Nile Region between the Eighth Century BC and the Sixth Century AD. Paperback, 1998, p. 898
} 


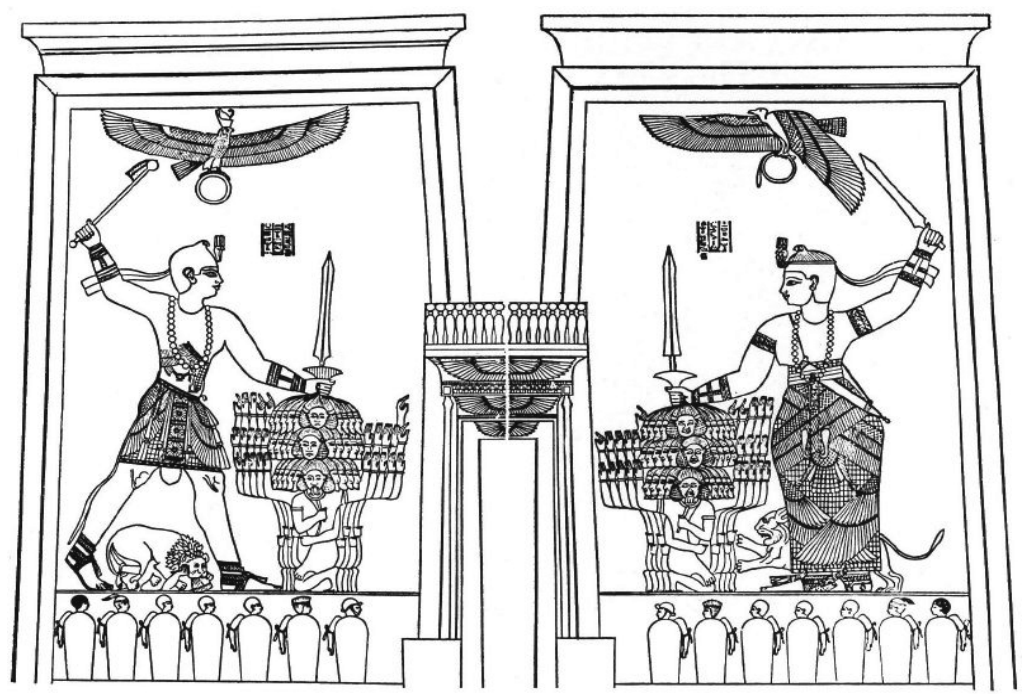

Figura 3. Amanitore e Natakamani no Templo de Apedemak, em Naga. Referência: SALES, José das Candeias. The ritual scenes of smiting the enemies in the pylons of Egyptian temples: symbolism and functions. In: POPIELSKA-GRZYBOWSKA, Joana e IWASZCZUK, Jadwiga. Thinking Symbols. Interdisciplinary Studies. Acta Archaeologica Pultuskiensia, Vol. VI. Department of Archaeology and Anthropology. Pułtusk, 2017.

Os soberanos são aqui representados com adornos e vestimentas tipicamente meroíticos, enquanto sua atitude de domínio e triunfo sobre os inimigos remonta a um estilo de iconografia egípcia, como já nos referimos anteriormente. Observamos que ambos assumem uma posição central e possuem em uma das mãos um símbolo de força e vitória sobre os cativos, e na outra, estes aparecem amarrados segurados por seus cabelos. Esta forma de representação dos prisioneiros os mostra em um conjunto tripartido, onde trinta deles são divididos em três linhas e a figura central de cada uma delas é mostrada em sua face, enquanto as figuras centrais formam um eixo quase reto. ${ }^{57}$ Este tipo de iconografia foi adaptada e reajustada a partir de representações egípcias de domínio de cativos, como podemos observar a partir da análise da imagem de Ptolomeu XII, presente no Templo de Isis, em Philae.

\footnotetext{
${ }^{57}$ WOB, Florian. The representation of captives and enemies in meroitic art. In: $\mathrm{ZACH}$, Michael H. (edit). Proceedings of the 11th international conference for meroitic studies. Viena, $1-4$ de setembro, 2008, p. 588.
} 


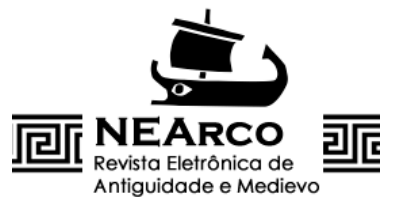

Revista Eletrônica de
Antiguidade e Medievo
NEARCD: Revista Eletrônica de Antiguidade 2020, Volume XII, Número II - ISSN IS882-8713

Núcleo de Estudas da Antiguidade - NEA

Universidade do Estado do Rio de Janeiro

ISSN 1982-8713

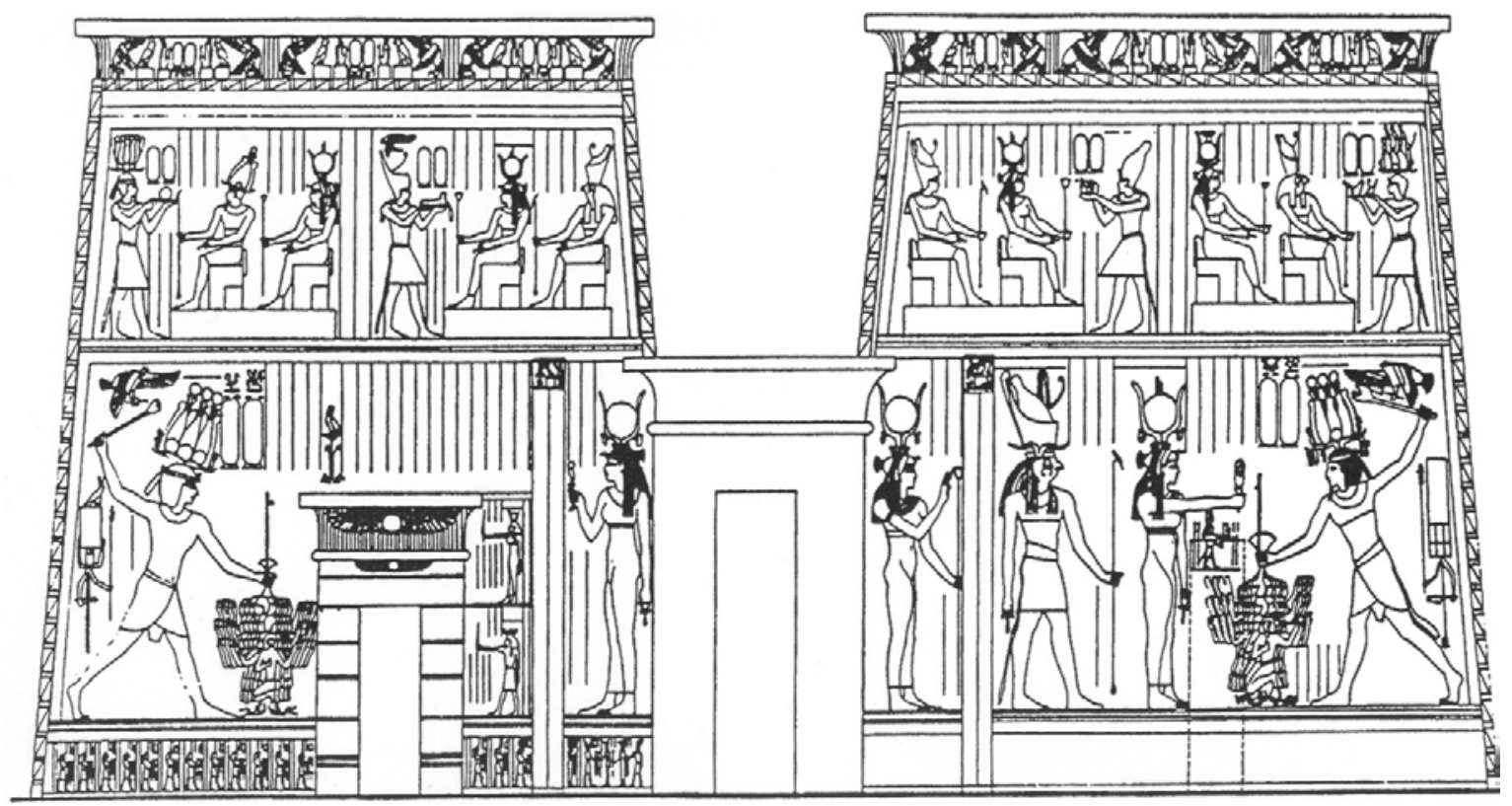

Figura 4. Ptolomeu XII dominando cativos no Templo de Isis, em Philae. Referência: Fonte: SALES, José das Candeias. The ritual scenes of smiting the enemies in the pylons of Egyptian temples: symbolism and functions. In: POPIELSKA-GRZYBOWSKA, Joana e IWASZCZUK, Jadwiga. Thinking Symbols.

Interdisciplinary Studies. Acta Archaeologica Pultuskiensia, Vol. VI. Department of Archaeology and Anthropology. Pułtusk, 2017.

Observando as duas cenas, podemos perceber as similitudes e os ajustes feitos pela arte meroítica em relação a egípcia. Ptolomeu XII é retratado em uma pose que evidencia seu poder, segurando seus inimigos pelos cabelos, estando estes também em um conjunto tripartido e com suas mãos elevadas, como se estivessem declarando sua rendição e pedindo a clemência do soberano. Este se encontra pronto para sacrificá-los em honra a Isis, Hathor e Hórus e usa, além de serpentes uraei, a coroa hemhem. ${ }^{58}$

\footnotetext{
${ }^{58}$ SALES, José das Candeias. The ritual scenes of smiting the enemies in the pylons of Egyptian temples: symbolism and functions. In: POPIELSKA-GRZYBOWSKA, Joana e IWASZCZUK, Jadwiga. Thinking Symbols. Interdisciplinary Studies. Acta Archaeologica Pultuskiensia, Vol. VI. Department of Archaeology and Anthropology. Pułtusk, 2017, p. 260.
} 
ISSN 1982-8713

Ao compararmos esta cena com as representações de Natakamani e Amanitore, percebemos que os prisioneiros em ambas são mostrados de forma similar, sendo na representação meroítica possível observar com maior clareza o eixo central de cada linha. Os governantes de Méroe utilizam insígnias, vestes e símbolos de poder próprios desta sociedade, e, especialmente a presença do elemento feminino junto ao masculino em uma cena de conquista militar e de co-regência com igualdade de proporções nas representações são diferenças que nos parecem bastante relevantes.

Apesar das diferentes titulaturas utilizadas por eles, e a partir da reflexão sobre a iconografia apresentadas, observamos que Natakamani e Amanitore parecem ter assumido a mesma posição de importância enquanto soberanos, caracterizando um período de co-regência.

\section{Conclusão}

A partir das análises apresentadas neste artigo, refletimos sobre o lugar social do elemento feminino na sociedade africana kushita, buscando pensar em uma história da mulher que considere o papel exercido por esta enquanto inserida em um conjunto de relações culturais, históricas, sociais e econômicas próprias desta sociedade.

A mulher na sociedade kushita não assumiu um papel político preponderante apenas com a chegada das Candaces ao poder central, mas sua relevância já era observado junto ao governante enquanto mãe, irmã ou esposa, a partir da importância decisiva da descendência materna e do papel dessas mulheres como aquelas responsáveis por legitimar a coroação e o governo do soberano e também junto a participação efetiva em decisões políticas junto a seus filhos ou maridos. Considerando as análises das iconografias apresentadas, foi possível endossarmos nossa percepção sobre a existência de uma complementariedade entre o masculino e o feminino, nas relações estabelecidas em nosso espaço de pesquisa, sendo este formado por aqueles 
ISSN 1982-8713

que compunham a família dos governantes e também os que assumiam as funções de mais alto status político social e religioso.

Em Kush cada elemento, feminino e masculino, tinha seu papel essencial a ser desenvolvido, sem o qual não seria possível existir um equilíbrio social e político. Ainda que tenham assumido a função de soberanas autônomas e independentes em um período nesta sociedade, a ocupação deste lugar não se configura como uma divisão entre o masculino e o feminino tal qual consideramos no pensamento ocidental. Nos parece relevante pensar que estamos tratando de uma sociedade da África subsaariana na antiguidade, e que nesta, os valores e circunstâncias que concediam status proeminentes as mulheres diferiam dos quais anteriormente supomos.

\section{Referências Bibliográficas}

\section{Documento}

ESTELA DE HAMADAB. Museu Britânico. Departamento do Egito Antigo e Sudão, 1914. Disponível em: http://www.britishmuseum.org/research/collection online/collection object details. aspx?objectld=116018\&partld=1\&place=1843\&plaA=1843-3-1\&page=1. Acesso em 10 de abril de 2019.

\section{Bibliografia}

ADESINA, Jimi. Re-appropriating Matrifocality: Endogeneity and African Gender Scholarship. African Sociological Review 14 (1). 2010.

AMADIUME, Ifi. Re-inventing Africa: Matriarchy, Religion and Culture. Interlink Publishing Group, 1997.

A. M. ALI HAKEM. A civilização de Napata e Méroe. In: MOKHTAR, G. (coord.). História Geral da África. v. 2: A África Antiga. São Paulo - Paris: Ática - UNESCO, 1983.

A. M. ALI HAKEM. Quando as mulheres reinavam e Méroe. Correio da Unesco - volume 7, 1979. 
EIDE, Tormod et alli. Fontes Historiae Nubiorum: Textual Sources for the History of the Middle Nile Region between the Eighth Century BC and the Sixth Century AD. Paperback, 1998.

FAGE, J. D. The Cambridge history of Africa. Vol. 2: From c. 500 BC to AD 1050. Cambridge University Press, 2008.

GRAVES-BROWN, Carolyn. Dancing for Hathor. Women in Ancient Egypt. Londres e Nova York: Hambledon Continuum, 2010.

HARKLESS, Necia Desiree. Nubian pharaohs and meroitic kings - the kingdom of Kush. Bloomington: Author House, 2006.

LOHWASSER, Angelika. Queenship in Kush: Status, Role and Ideology of Royal Women. Journal of the American Research Center in Egypt 38, 2001, p. 61-76.

NOWOTNICK, Ulrike. (et al). Hamadab. Urban living at the Nile in Meroitic times. German Archaeological Institute Orient Department, Hamadab Archaeological Project, Berlin, University of Liverpool, 2014.

NUZZOLO, Massimiliano. The royal mother in the Ancient Egyptian Kingdom: role, representation and cult. In: Proceedings of the Second International Congress for Young Egyptologists, Lisboa, 23-26 October 2006, Lisboa 2009.

ROTH, Silke. Queen. In Elizabeth Frood, Willeke Wendrich (eds.). UCLA Encyclopedia of Egyptology, Los Angeles. UCLA, 2009.

SALES, José das Candeias. Organizando simbolicamente o panteão do antigo Egipto. As tríades divinas. Revista Mundo Antigo - Ano V, Vol. V, Nº9 - Maio - 2016.

SALES, José das Candeias. The ritual scenes of smiting the enemies in the pylons of Egyptian temples: symbolism and functions. In: POPIELSKA-GRZYBOWSKA, Joana e IWASZCZUK, Jadwiga. Thinking Symbols. Interdisciplinary Studies. Acta Archaeologica Pultuskiensia, Vol. VI. Department of Archaeology and Anthropology. Pułtusk, 2017.

SEVILLA CUEVA, Covadonga. El principio femenino de la realeza egipcia: Las divinas adoratrices de Amón. Madrid: Universidad Autónoma de Madrid, 1998.

TOROK, Laszlo. Between Two Worlds. The Frontier Region between Ancient Nubia and Egypt 3700 BC - AD 500. Leiden/Boston, Brill, 2009. 
NEARCD: Revista Eletrônica de Antiguidade 2020, Volume XII, Número II - ISSN IS82-8713

Núcleo de Estudas da Antiguidade - NEA

Universidade do Estado do Rio de Janeiro

ISSN 1982-8713

TOROK, Laszlo. The kingdom of Kush: handbook of the Napatan-Meroitic civilization. Handbook of Oriental studies. Brill, 1997.

TYLDESLEY, J. Chronicle of the queens of Egypt. London: Thames \& Hudson, 2006.

WOB, Florian The representation of captives and enemies in meroitic art. In: ZACH, Michael H. (edit). Proceedings of the 11th international conference for meroitic studies. Viena, 1 - 4 de setembro, 2008. 